\title{
Processos migratórios na fronteira Brasil-Guiana ${ }^{1}$
}

\author{
MARIANA CUNHA PEREIRA
}

$\mathrm{O}$ SUDOESTE DA Guiana e o norte do Brasil estão separados pelo Rio Tacutu. Do lado brasileiro está o vale do Rio Branco, que corresponde à área norte da fronteira, onde se localiza o Estado de Roraima. Observado a partir daí, trata-se de uma fronteira de grande importância no contexto histórico da Região Norte. No passado, associava-se ao fornecimento de mão-de-obra escrava indígena para o Estado do Pará (Farage, 1991, p.68). Também se revelam como o espaço da busca do Eldorado, iniciada pelos colonizadores espanhóis e holandeses, além de ter sido o território de ocupação portuguesa, que ocorreu já com a presença de outros colonizadores na área. Região de demarcação de limites internacionais, também retrata os conflitos dos povos indígenas ante a política de ocupação que se implementou no governo brasileiro da época.

Conforme Santilli (2001), os problemas demográficos em razão da baixa taxa populacional assumiam maior relevância diante dos conflitos internacionais, visto que isso questionava a legitimidade do domínio português; entretanto, ao tornar essa região um Território Federal em 1943 - o território de Roraima -, ocorreu a construção mínima de uma infra-estrutura física e administrativa.

O grande boom da expansão populacional e de acenos para um possível desenvolvimento veio, segundo Rodrigues (1996), com o incentivo à migração, com projetos de assentamentos e de colonização agrícola implantados a partir de 1970, com os vários momentos de intensificação do garimpo como atividade econômica nos anos 1980 e com a criação do Estado de Roraima em 1988.

Faço aqui uma incursão sobre os aspectos geográficos da Guiana; a idéia é mostrar como se produzem, então, os processos migratórios no recorte que fiz da fronteira Brasil-Guiana, que se delimita no espaço fronteiriço articulado entre as cidades de Boa Vista, Bonfim (Br.) e Lethem (Gy), sobre as quais falo em seguida.

A República Cooperativista da Guiana, único país colonizado pelos ingleses no continente da América do Sul e banhado pelo Mar do Caribe, culturalmente se assemelha mais às nações caribenhas que às sul-americanas. Desde a época dos holandeses, sua maior produção tem sido o açúcar e o arroz, que predominou na área costeira. Do ponto de vista da divisão político-administrativa, a Guiana, segundo Smith (1962), divide-se em três grandes faixas de regiões ecológicas, a saber: uma zona litoral ou costeira, a floresta e a savana. Quanto à sua divisão político-administrativa, apresenta dez regiões, comu- 
mente denominadas segundo números ou nomes correlacionados às bacias hidrográficas e localizações.

Segundo Colina (1997, p.1), a mão-de-obra escrava indígena não se adequou a essas atividades produtivas: "Los indigenas, tribus descendientes del tronco arahuaco, se negaron a colaborar en los trabajos cañeros por considerarlos muy $d u$ ros y no pudieron ser sometidos por lãs armas, por lo que emigraron hacia lãs zonas selváticas del sur, donde se asentaron finalmente". Esse fato concorreu para que se percebesse a necessidade de introduzir a mão-de-obra escrava negra oriunda da África.

O ritmo de desenvolvimento da Inglaterra, somado aos interesses dos colonos ingleses plantadores, instalados nessas colônias, e os primeiros passos da revolução industrial levaram, porém, a Inglaterra a decidir-se pelo trabalho assalariado. Segundo Smith (1962, p.34), “Os centros de sustentação para o ataque em cima da escravidão eram os centros industriais, particularmente no norte da Inglaterra, onde a prosperidade estava tornando-se cada vez mais dependente do comércio livre". Foi o processo de acumulação da economia inglesa, durante os primeiros quarenta anos do século XIX, com desenvolvimento social e controle social, que favoreceu a transição do modo de produção escravista para o modo livre.

Há, no entanto, um outro elemento significativo para o fim da escravidão na Guiana: são as missões que se instalaram em colônias britânicas. A ação dos missionários contribuiu para que os escravos tomassem posturas diante de sua condição escravista. Enfim, a escravidão na Guiana acabou em 1837, decorridos trinta anos do final do tráfico de escravos. ${ }^{2}$

A substituição da mão-de-obra escrava levou àquele país uma massa de trabalhadores contratados, oriundos principalmente do oeste da Índia. ${ }^{3}$ Isso dinamizou as relações entre os grupos étnicos ali existentes. $\mathrm{O}$ cenário interno e externo colaborou para a relativa autonomia (1928) daquela colônia, e isso culminou, em 1961, com a promulgação da Constituição e sua posterior independência em 1966.

A bibliografia sobre a Guiana, ao relatar sobre a Revolta do Rupununi, conflito armado que ocorreu na fronteira com o Brasil, aponta como uma das causa da revolta a migração dos indianos para a Guiana no sistema de labor migration, isso teria deixado um grupo social, os rancheiros, insatisfeito, preocupados que seu poder econômico e político ficasse delimitado à região.

Do outro lado da fronteira, no Brasil, a cidade de Boa Vista, elevada à condição de capital do Estado de Roraima, na década de 1980 a 1990, período que corresponde à descoberta de novos garimpos, concentrava $50 \%$ da população do Estado. Observa-se, pelos dados do Quadro 1, que a maioria dos migrantes que povoam atualmente o Estado chegou entre o período de 1996 a 2000, incentivada pela busca de melhores condições de vida e trabalho, sendo, em sua maior parte, de origem nordestina (Rodrigues et al., 2002). É significativo acentuar 
esse dado referente ao crescimento demográfico de Boa Vista, porque essa, das cidades que compõem a região de fronteira, além de ser a mais desenvolvida, é a referência nos serviços públicos e na relação comercial que envolvem os sujeitos sociais que fazem o trânsito migratório. Portanto, a alteração em seu quadro demográfico representa dados significativos de análise para a conjuntura socioeconômica e cultural da região fronteiriça.

Entendo que todo quadro migratório, como um dado estatístico apreendido de um recorte temporal, revela uma informação conjuntural, por isso precisa de esclarecimento. Por exemplo, o recorte de 1996 a 2000 reforça a observação de que houve um crescimento significativo daquela população decorrente do “boom do garimpo". Naquela ocasião, tomou conta do país a idéia em relação a Roraima de um novo "Eldorado", e uma massa significativa de excluídos da população nordestina migrou para aquele Estado. Rodrigues et al. (2002) explicam que o dado de 2001 já aponta, no entanto, para um decrescimento, talvez decorrente da queda do garimpo, e exemplifica com a diferença que vem surgindo no perfil dos migrantes: agora mais acentuada a população feminina em comparação com a masculina, segundo dados do IBGE a partir de 2000.

Além disso, Roraima, desde a segunda metade dos anos 1990, está vivendo "uma febre de concursos públicos". Apesar da conjuntura de acentuados escândalos políticos envolvendo o aparelho do Estado, diz-se que eles servem para "moralizar a administração pública, com a efetivação dos profissionais em suas carreiras profissionais”. Esse fato está contribuindo para levar àquele Estado um outro perfil de migrante, agora desenhado pelo aspecto profissional.

Na mesma perspectiva de entender o processo migratório como conjuntural, o diretor do IBGE de Roraima, na ocasião desta pesquisa, numa análise mais abrangente, referindo-se ao processo migratório da região de fronteira, alerta para os aspectos constitutivos que se associam e explicam os fatores diversos que provocam a migração e, além disso, chama a atenção para o aspecto oscilante desse processo e ainda para o perfil do migrante naquela região de fronteira. Suas palavras se refletem em minha observação de campo e muito contribuíram para justificar por que é tão significativo entender Boa Vista e Bonfim do ponto de vista dos movimentos migratórios. Vejamos sua interpretação:

A mesma coisa que é bastante complicado, por exemplo, em Roraima é você fazer, entender o movimento migratório [...] Porque você acaba concluindo que a partir do momento que (vêm) cinco ônibus lotados de Manaus na rodoviária internacional de Boa Vista, isso significa coisa de cento e cinqüenta pessoas, diariamente, descendo em Boa Vista. Mas, nós esquecemos um detalhe: todo dia, também, sai cinco ônibus lotados que vai embora. (muito freqüente em) períodos eleitorais [...] Agora o que se observa é que é um estado de fronteira. É um estado que ele absorve, efetivamente, as famílias que estão a margem de outros estados, principalmente do nordeste. No entanto, nós temos um mercado se desenvolvendo. Só que esse mercado está sendo exigente com relação à mão-de-obra. E nós temos carência de mão-de-obra $\mathrm{e}$ temos sobra de mão-de-obra desqualificada. É isso que está ocorrendo. 
Alguns aspectos dessa fala levam-nos a apreender o dialético processo migratório que mostra o movimento diário, de sonhos e decepções, daqueles que fazem o trânsito transfronteiriço interno e externo da Região Norte brasileira. Levam-nos também a perceber o quanto se torna complexo caracterizar, do ponto de vista da migração, Roraima e as cidades fronteiriças em estatísticas que revelam informações de longo prazo. O que se pode dizer é que o fluxo migratório levou a mudanças que hoje se refletem nas exigências do mercado de trabalho, modificando, com isso, aos poucos, as perspectivas que se apresentam para essas cidades.

Impõe-se, portanto, a importância do dado demográfico, que - como mostra o Quadro 1 - apresenta em Boa Vista as proporções visíveis do crescimento e, ao mesmo tempo, permite deduzir, pela ausência, que Bonfim não é referência para o processo migratório interno do Brasil. No entanto, constitui a maior referência para a migração estrangeira oriunda da Guiana, como discuto a seguir.

Quadro 1 - Destino dos migrantes para os municípios do Estado

\begin{tabular}{l|r|r|r|r|r|r}
\hline \multirow{2}{*}{$\begin{array}{c}\text { MUNICÍPIOS DE } \\
\text { DESTINO DE } \\
\text { INDIVÍDUOS }\end{array}$} & 1996 & 1997 & 1998 & 1999 & $\mathbf{2 0 0 0}$ & $\begin{array}{r}\text { Total do } \\
\text { Período 96/00 }\end{array}$ \\
\cline { 2 - 7 } & 08 & 50 & 311 & 89 & 11 & 469 \\
\hline Alto Alegre & 7.018 & 4.745 & 12.297 & 10.542 & $\mathbf{8 . 3 3 8}$ & $\mathbf{4 2 . 9 4 0}$ \\
\hline Boa Vista & $-x-x-$ & 20 & 17 & 05 & 03 & 45 \\
\hline Cantá & 129 & 159 & 171 & 219 & 157 & 835 \\
\hline Caracaraí & 36 & 19 & 46 & 105 & 45 & 251 \\
\hline Caroebe & 07 & 35 & 209 & 124 & 125 & 500 \\
\hline Iracema & 30 & 121 & 231 & 56 & 76 & 514 \\
\hline Mucajai & 05 & 09 & $-x-x-$ & 10 & 19 & 43 \\
\hline Pacaraima & 290 & 499 & 1.265 & 1.613 & 1.111 & 4.778 \\
\hline Rorainópolis & 69 & 97 & 207 & 157 & 86 & 616 \\
\hline São João da Baliza & 94 & 26 & 77 & 114 & 105 & 416 \\
\hline São Luiz do Anauá & 20.454 & 5.780 & 14.831 & 13.034 & 10.078 & 64.181 \\
\hline Total Geral & & & & & & \\
\hline
\end{tabular}

Fonte: Secretaria do Bem-Estar Social/Departamento de Desenvolvimento Social (cf. Rodrigues et al., 2002).

Sobre a população de Roraima, tendo como foco de análise Boa Vista e Bonfim, respectivamente, é também significativo destacar as informações quanto ao gênero, às áreas urbana e rural e à faixa etária. No aspecto de gênero, o Estado de Roraima, pelo censo de 2000, informa que a população cresceu de forma a concentrar maiores índices demográficos na capital, um pouco estabilizados entre homens e mulheres, porém nem tanto quanto à faixa etária. Quanto à distinção entre urbano e rural, a população em Boa Vista é de 197.098, enquanto na área rural ela é de 3.470; Bonfim, diferentemente, apresenta três mil 
na área urbana, e 6.326 na área rural. Um outro aspecto é a análise da faixa etária: Roraima é um Estado eminentemente de população jovem, que se concentra na capital, quando se compara Bonfim a Boa Vista; no entanto Bonfim também apresentará, em breve, uma população jovem majoritária, conforme se deduz a partir dos dados das fases anteriores, de criança e de adolescente.

O trânsito migratório naquela região, além de caracterizar os processos migratórios de pessoas, explica, também, os deslocamentos de mercadorias e de significados simbólicos de um lado a outro entre esses Estados-nação. Além das mercadorias, há um intercâmbio de etnias e nacionalidades em torno do interesse comercial. As observações de campo, que se confirmaram por entrevistas locais, apontam que, no mercado informal, a composição étnica assim se distribui: 1) os barraqueiros, que são, em sua maioria, guianenses que se estabelecem em Boa Vista e Bonfim; 2) os atravessadores, a maior parte é de brasileiros regionais ${ }^{4}$ (notadamente no comando da venda de peixes e de produtos hortigranjeiros); 3 ) os indígenas, que estão na feira em três situações: a) os de diferentes nacionalidades (incluindo bolivianos), que vendem pequenas mercadorias industrializadas, na condição de vendedores ambulantes (sem barraca), b) os indígenas barraqueiros (especialmente brasileiros), que vendem produtos hortigranjeiros e temperos e são moradores de Boa Vista, e c) os indígenas das malocas que, com apoio das prefeituras municipais, trazem suas produções para serem comercializadas - a farinha, o milho, o arroz, a mandioca e poucas peças artesanais.

Todo esse quadro explica um perfil de migrante indocumentado, nos dois lados da fronteira; portanto, não é possível encontrar dados estatísticos que expressem a presença dos migrantes das duas nacionalidades aqui em questão. No entanto, a história de Bonfim nos mostra alguns elementos históricos, políticos e simbólicos dessa questão.

O município de Bonfim limita-se a oeste com o município de Boa Vista e fica a 125 quilômetros da capital, percurso que se faz pela BR-401. A leste, situa-se a cidade de Lethem, da República Cooperativista da Guiana, com a qual faz fronteira. Surgiu no século XIX, quando um baiano, Sr. Manoel Luiz Silva, em homenagem ao padroeiro de sua terra natal, o Senhor do Bonfim, deu início à moradia naquelas terras. Com uma história marcada por fases de picos de povoamentos relacionados às atividades de expansão agrícola, fomentação do comércio de fronteira, instalação do Pelotão do Exército, abertura de estradas, revolução guianense e catequização indígena, esse município já experimentou momentos específicos de atenção nacional, mas hoje se encontra numa situação menos prestigiada.

O período da expansão agrícola relaciona-se à presença de grandes fazendas de gado que atraiu e concretizou uma política de fomento ao empreendimento agropecuário predominante entre 1910 a 1960. Até essa última década, o comércio com a Guiana era favorável àquele país, mas voltou-se mais para o lado brasileiro da fronteira, no final de 1960, impulsionado por dois motivos: primeiro, a revolução guianense, porque se implementou a partir desse evento 


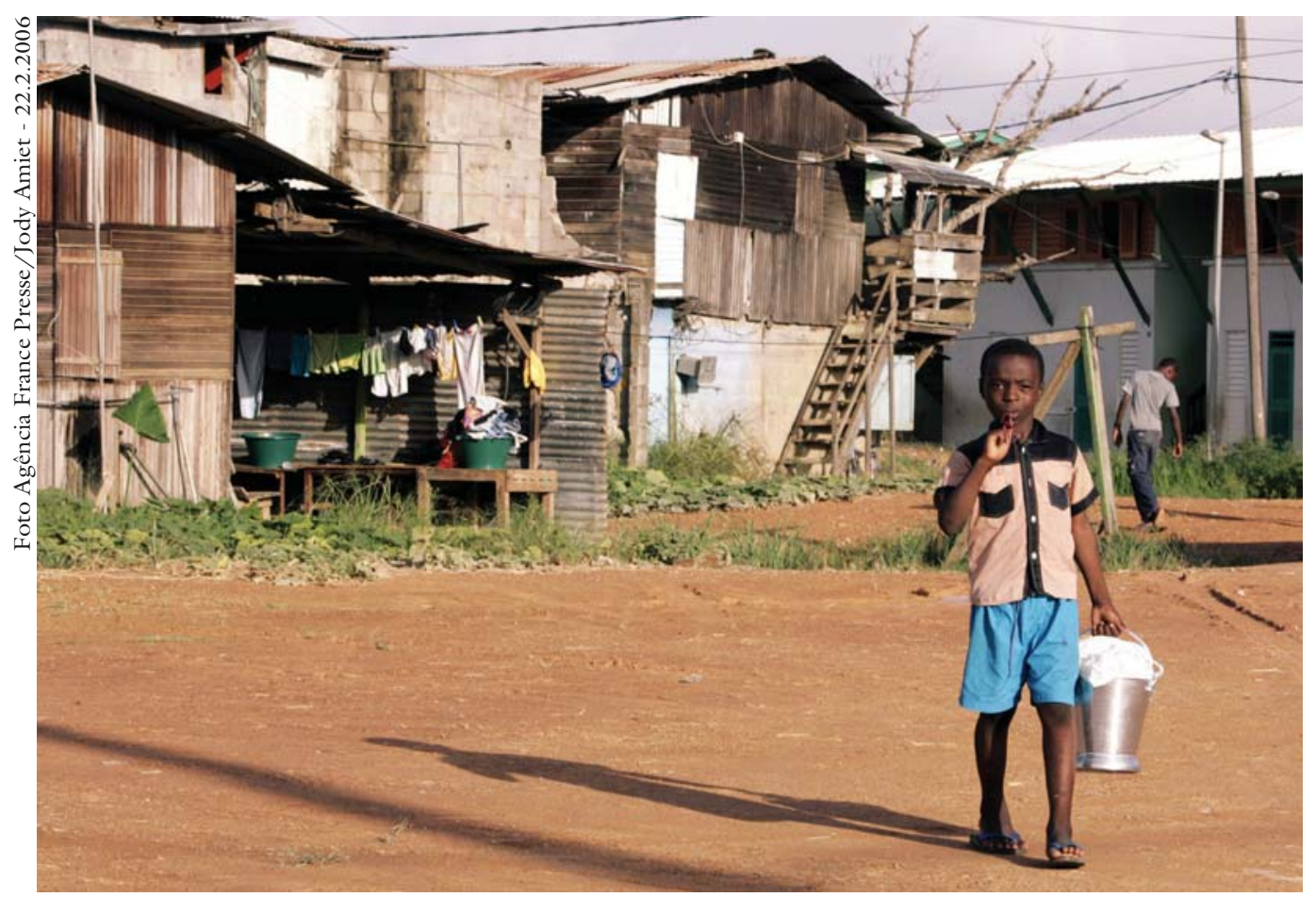

Criança moradora da periferia de Caiena, capital do Departamento de Ultramar da França.

um comércio de bens de consumo alimentícios que perdura até hoje; e segundo, a instalação do $1^{\circ}$ Pelotão Especial de Fronteira, que dinamizou ainda mais o comércio com a chegada das famílias dos militares. No entanto, desde os anos 1970, a construção das BR facilitou o acesso aos mercados de Boa Vista, Manaus e Santa Elena de Uairén, na Venezuela, e isso tem diminuído a importância de Bonfim no setor comercial.

Dois outros momentos de impulso de povoamento e instalações de infraestrutura ocorreram por volta de 1968 a 1978. Em 1968, chegou a Bonfim uma missão protestante para catequizar os índios da região. Com eles, a cidade ganhou uma igreja católica e uma escola primária. Entre 1969 e 1978, assentaramse dezenas de famílias oriundas do Nordeste brasileiro em razão dos projetos de colonização da Amazônia, a exemplo do Calha Norte e Poloamazônia, que abriram novas fronteiras agrícolas.

Há em Boa Vista colônias agrícolas, implantadas desde o período das políticas de povoamento do Estado por meio de vilas de colonos. Essas colônias agrícolas estão encravadas entre as terras indígenas macuxi e wapixana. Em geral, o convívio entre colonos e indígenas é amistoso e, segundo depoimentos, é cada vez mais intenso em virtude dos casamentos interétnicos, porém não menos carregado dos estereótipos que naturalizam as diferenças culturais vivenciadas no dia-a-dia.

Bonfim, como sinalizei linhas atrás, não consta no quadro que apresenta os dados sobre os municípios mais procurados para a migração interna no Brasil (ver Tabela 1), uma vez que não apresenta os atrativos mais comuns da migra- 


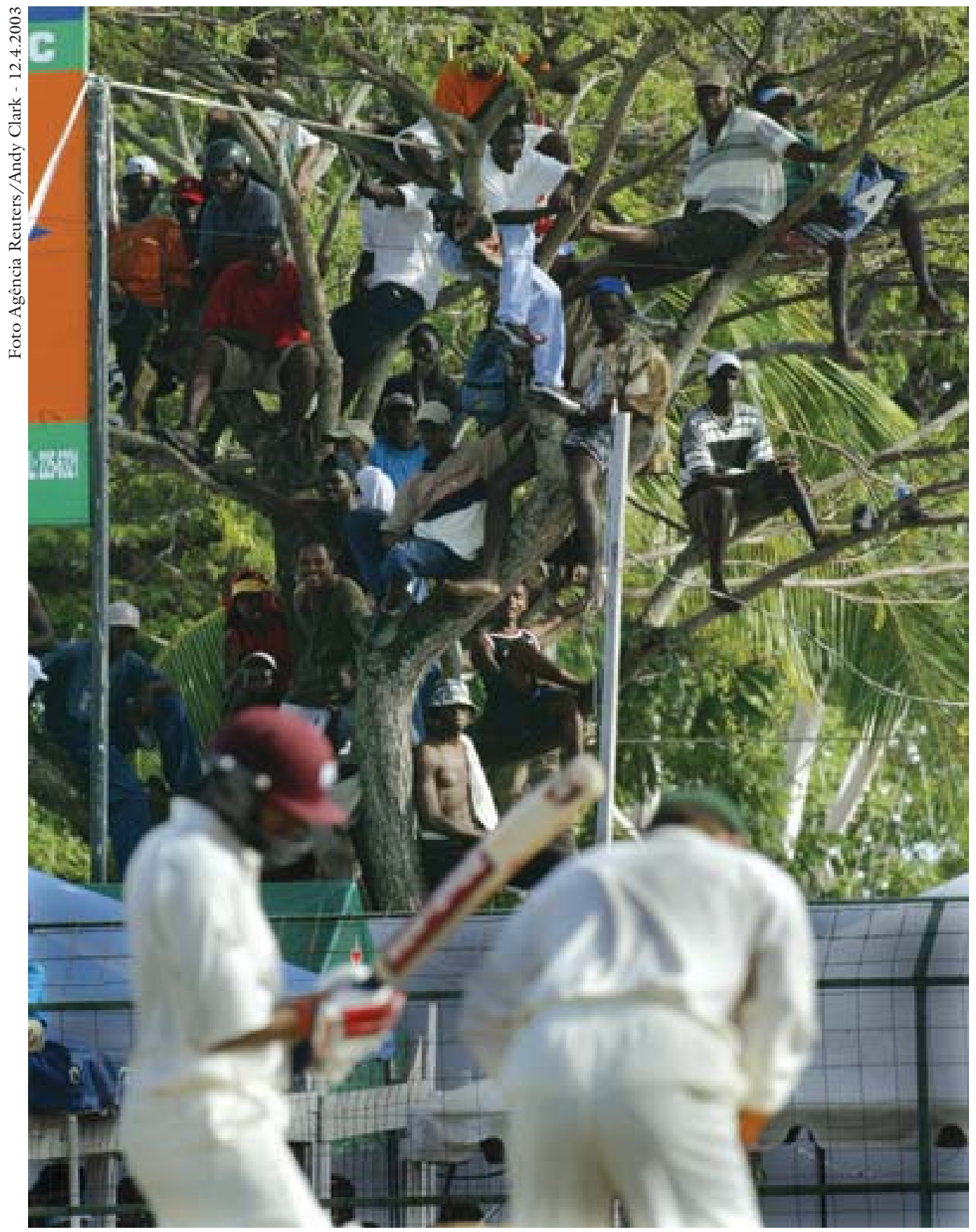

Jogadores de cricket de Georgetown, na Guiana, são observados por colegas durane um teste.

ção, quais sejam, desenvolvimento comercial e áreas de garimpo; mas, segundo depoimentos de moradores locais e de autoridades, sabe-se que há migração guianense para essa cidade, originária do final da década de 1960, depois que a Guiana tornou-se independente. Tanto os moradores comuns quanto as autoridades locais reconhecem que $70 \%$ da população de Bonfim é composta de guianenses, mas os dados do IBGE não confirmam essa informação. Isso se explica porque, conforme informa o diretor do IBGE, o censo questiona em primeiro 
lugar quantos são os moradores daquela cidade; por isso, ao ser feito, não prioriza a nacionalidade.

O censo cataloga o morador, mas o informe sobre o migrante, nesse caso, é evitado, pois as pessoas preferem identificar-se como moradoras de Bonfim e, de certa forma, escondem sua origem nacional. O que decerto deve ficar confuso também para o recenseador. Talvez isso explique o não-destaque quanto à origem migratória e a indicação da nacionalidade em Bonfim em tabelas do IBGE consultadas. De todo modo, isso torna impossível o dado estatístico quanto à nacionalidade no sentido que interessa a esta discussão, porque a identificação de não ser morador de origem e, por conseguinte, ser estrangeiro esbarra na auto-atribuição e na atribuição que nesse caso se liga a uma dupla identidade nacional que pode ser negociada, a identidade étnica, e a identidade nacional é negociada conforme as relações de saber/poder que estiverem em jogo.

Reconheço aqui a importância de estudar os processos migratórios de acordo com o recorte étnico-racial com base nas referências de atribuição e auto-atribuição conjugadas com a peculiaridade da cultura local. Vê-se que os dados estatísticos não expressam o que de fato a observação etnográfica aponta, a população indígena é majoritária em Bonfim, e não apenas um terço como os dados estatísticos demonstram; a classificação étnica negra dependerá da identificação pelas cores parda e preta.

Os dados etnográficos daquela região de fronteira quanto à discussão sobre percentual de negros no Brasil são menos destoantes quando se comparam com os dados do IBGE, visto que o negro na fronteira é sempre o estrangeiro guianense, e o brasileiro é apenas "mais moreno" diante das nuanças da cor na identificação que se faz segundo um referencial do racismo à brasileira, o que acaba definindo o negro no mesmo escore, uma vez que politicamente se soma o pardo e o preto para definir quem é negro no Brasil, segundo a interpretação do movimento social.

Lethem está às margens do Rio Tacutu, a composição espacial da cidade lembra uma vila não muito habitada; muitos terrenos baldios separam as casas residenciais e comerciais.

A cidade de Lethem possui uma população de aproximadamente dois mil habitantes. Do ponto de vista étnico, a predominância é dos negros, seguida dos indo-guianenses e indígenas.

Há um fluxo migratório constante de brasileiros em direção a Lethem. Eles se movem pela comercialização de produtos, como açúcar e alho, e pela busca de trabalho no garimpo. Nesse caso, adentram o território guianense. Do mesmo modo, os guianenses deslocam-se para Bonfim e Boa Vista no intuito de vender seus produtos e procurar empregos em serviços de baixa qualificação. Ainda, como pude observar, para ambos os povos, outro motivo dos deslocamentos diários é a busca por serviços públicos (saúde e educação) nos dois lados. Porém, alguns desses deslocamentos acabam tornando-se migração. 
Na viagem que se faz de Boa Vista a Lethem, transcorre-se o percurso até Bonfim, no coletivo, e a única empresa oferece aquela linha de serviço em quatro horários distribuídos ao dia. A Polícia Federal (PF) vistoria o ônibus, solicita a cada passageiro que apresente o documento de identidade e convida aqueles que não o possuem a descer - aliás, não permitem a viagem de crianças sem documentação. Entre Bonfim e Lethem, em território do Brasil, há um posto de fiscalização, antes da margem do rio, que fica aproximadamente uns cinco minutos a pé. Nesse posto, só se faz vistoria em carros de carga quando esses fazem a travessia na balsa. Solicitam ao transeunte o passaporte, caso deseje adentrar no território guianense, para além de Lethem.

A diferença dessa política de controle entre as duas nações é indicativa de como se organiza o cotidiano na fronteira. Ali a circulação de mercadorias tem, por conseguinte, um controle expresso no percurso que se faz do Brasil para a Guiana e, nesse sentido, só há controle no território brasileiro. Assim, o que sai da Guiana para o Brasil passa por Bonfim e pode até sair do Estado de Roraima por outras cidades, sem passar pelo controle da PF em Boa Vista. Mesmo com a existência de um posto de fiscalização em Bonfim, não há grandes preocupações com mercadorias que se trazem da Guiana, visto que carros pequenos, que se dirigem da margem do rio à rodoviária de Bonfim, passam pelo posto sem a vistoria dos policiais. Eles apenas observam os comportamentos dos passageiros. A PF também realiza um controle na BR-401, que liga Bonfim a Boa Vista; nesse caso, vistoriam até os ônibus. Também, periodicamente, um policial federal acompanha, de forma discreta, a movimentação de bagagens que se despacham na única empresa de ônibus, de Bonfim que faz a linha para Boa Vista, Normandia e Pacaraima.

Observa-se, portanto, que os processos migratórios de pessoas e de mercadorias na fronteira articulam, a um só tempo, cultura, identidade, nacionalidade e localidade. Conseqüentemente, para além dos aspectos dos dados estatísticos e geopolíticos dessas três cidades, falar sobre Boa Vista, Bonfim e Lethem é, também, narrar as várias formas de migração que se produzem. São deslocamentos físicos e de significados, conforme os aspectos da interação social que servem à comparação e também retratam as várias formas de ser migrante na fronteira Brasil-Guiana.

Notas

1 Texto extraído da tese: A ponte imaginária: o trânsito de etnias na fronteira BrasilGuiana.

2 A longa polêmica em torno da ação junto aos escravos do missionário reverendo John Wray, em Demerara, transformou-se em 1823 na maior revolta de escravos da América do Sul.

3 Um estudo comparativo que Richardson (1975) realizou entre 1967-1971 entre Guiana e Trindade a respeito do tipo de migração para o trabalho e o estabelecimento de 
mobilidade entre padrões de plantation no sul do Caribe explica que, após a libertação dos escravos nesses dois países, os homens negros livres estabeleceram assentamentos de plantação na periferia e deram início ao trabalho de meio período. $\mathrm{O}$ autor, ao fazer a sua análise sobre os anos 1970, explica que, pela forma como esses homens livres da Guiana e Trindad e (posteriormente) os trabalhadores migrantes trazidos no indentured period se organizaram em vilas de plantações pelas terras do interior, é possível compreender como eles atravessaram o século XIX para se organizarem socioeconomicamente. Explica também que em tão poucos países existiram vilas de plantações periféricas em que os agricultores eram auto-suficientes e com problemas ecológicos tão semelhantes como os da Guiana e Trindad que faziam seus moradores procurar fonte de renda fora da vila. A formação da sociedade guianense moderna não resulta em aspectos muitos diferentes dos do Brasil quanto à migração para o trabalho. Os estudos de Richardson esclarecem, também, que esses trabalhadores contratados, no caso da Guiana, chegaram ao espantoso número de 250 mil. Trabalharam nas plantações e produção de açúcar e foram contratados para viver de forma muito precária. Assinavam um contrato de cinco anos de trabalho que, se renováveis por mais cinco anos, lhes garantiria a passagem de volta à Índia.

4 Os brasileiros regionais aqui são identificados como os moradores de todo o norte do Estado, enfim, das cidades vizinhas a Bonfim e Boa Vista.

Referências bibliográficas

COLINA, O. R. Guyana em 1969: "La insurreccion de Rupununi" <www.monografia. com>, publicado em 1997. Acessado em 14.7.2005.

FARAGE, N. As muralhas dos sertões: os povos indígenas no rio Branco e a colonização. Rio de janeiro: Paz e Terra, Anpocs, 1991.

RICHARDSON, B. Plantation Infrastructure and Labor Mobility in Guiana and Trinidad. In: SAFA, H.; TOIT, B. M. Du. (Ed.) Migration and Development: Implications for Ethnic Identity and Political Conflict. Paris: Mouton Publishers, 1975. p.205-24.

RODRIGUES, F. dos S. "Garimpando" a sociedade roraimense: uma análise da conjuntura sociopolítica. Belém, 1996. Dissertação (Mestrado) - Universidade Federal do Pará.

RODRIGUES, F. dos S. et al. Relatório Estadual - Tráfico de mulheres, crianças e adolescentes para fins de exploração sexual, realizado nos municipios de Boa Vista e Pacaraima/RR/Brasil e Santa Elena do Uairén/Venezuela. S. 1., 2002.

SANTILLI, P. Pemongon Pata: território macuxí, rotas de conflito. São Paulo: Editora Unesp, 2001.

SMITH, R. T. British Guiana. London: Oxford University Press, 1962.

RESUMO - NESSE TEXTO elaboro uma discussão sobre os processos migratórios que caracterizam a fronteira Brasil-Guiana. São elencados aspectos históricos, sociais, culturais das cidades que compõem aquela região de fronteira e também da vida local dos grupos étnicos que ali vivem um deslocamento contínuo ou permanente, aqui entendido como migração.

PALAVRAS-CHAVE: Processos migratórios, Etnia, Nacionalidades, Brasil, Guiana. 
ABSTRACT - THIS TEXT discusses the migratory processes that characterize the BrazilianGuyanese border, and lists the historical, social, and cultural aspects of the frontier cities and of the local lives of ethnic groups that experience continuous or permanent dislocation, here understood as migration.

KEYWORDS: Migratory processes, Ethnicity, Nationalities, Brazil, Guyana.

Mariana Cunha Pereira é doutora em Antropologia Social: estudos comparativos das Américas e Caribe / CEPPAC-UnB; mestre em Educação, subárea Antropologia da Educação pela Universidade de Brasilia (UnB). É especialista em Administração em Educação: Política, Planejamento e gestão. @-mcunhap@yahoo.com.br

Recebido em 15.5.2006 e aceito em 22.5.2006. 